\title{
Maternal and Perinatal Outcome in Adolescent Pregnancies as Compared to Adult Pregnancies
}

Bishal Khaniya ${ }^{1}$

${ }^{1}$ Department of Obstetrics and Gynecology, Institute of Medicine,

Maharajgunj, Kathmandu, Nepal.

Correspondence:

Dr. Bishal Khaniya. Email: bishalkhaniya92@gmail.com

Introduction: Adolescence is the period between the ages of 10-19 years that encompasses time from onset of puberty to full legal ages (WHO 2002).

Objective: The objective of the study was to explore effect of maternal ages on fetomaternal and perinatal outcome.

Methods: This is a hospital based retrospective case-control study conducted over 1 year (March 2017 to February 2018) in the department of Obstetrics and Gynaecology in Tribhuvan University Teaching Hospital to study the antenatal complications and perinatal outcome in adolescent pregnant women as compared to pregnant women of age 20-30 years.

Results: During this study period, there were 4980 deliveries out of which adolescent pregnancy were 140 (2.8\%). Anemia was significantly more in teenage group ( $16.42 \%$ vs $8.57 \%, p=0.047)$. Incidence of hypertensive disorders was $5.71 \%$ and $1.42 \%(\mathrm{p}=0.05)$ in teenage and adult group. Proportion of babies with intrauterine growth restriction was $5.71 \%$ in teenage and $1.42 \%(\mathrm{p}=0.05)$ in adult group. Low birth weight babies were significantly higher in teenage group than adult group $16.42 \%$ vs $8.57 \%$ ( $\mathrm{p}=0.047)$. NNU admission and apgar score were significantly higher in teenage group $5.71 \%$ vs $1.42 \%$.

Conclusion: Teenage pregnancies are associated with adverse obstetric and perinatal outcome.

Keywords: Adolescent; Outcome; Pregnancy.

\section{INTRODUCTION}

Adolescence is the period between the ages of 10-19 years that encompasses time from onset of puberty to full legal ages (WHO 2002). ${ }^{1}$ Every year an estimated 21 million girls aged 15 to 19 years and 2 million girls aged under 15 years become pregnant in developing countries. $^{2,3}$ In Nepal adolescent aged 10-19 years comprise of 6.38 million of the total population of 28.5 millions. ${ }^{4}$ In Nepal, the legal minimum age of marriage for women is 20 years. ${ }^{5}$ Nepal Demographic and Health Survey (NDHS) 2016 reported that 17\% of teenage girls had already given birth or were pregnant with their first child. ${ }^{6}$ Inadequate antenatal care, lack of education and poor socioeconomic status also affect the outcome. ${ }^{7,8,9}$ Adolescent pregnancies are also at increased risk for neonatal complications as premature, low birth weight, IUGR, still birth. ${ }^{10}$ Harrison et al reported increased rate of maternal mortality in young pregnant girls (27/1000) compared to (4/1000) in women aged 20- 24 years. ${ }^{11}$ It has been projected that incidence of adolescent pregnancy will rise by 2030 due to early engagement of adolescents in sexual life and reluctance and ignorance of contraception. ${ }^{12}$

Citation: Khaniya B. Maternal and perinatal outcome in adolescent pregnancies as compared to adult pregnancies. Nepal J Health Sci. 2021 Jan-Jun;1(1): 43-47 
There is a need to study the effect of maternal age in determining obstetrics outcome to reduce maternal morbidity and mortality in our settings. This study will help us to recommend the optimal age of childbirth to reduce maternal and perinatal morbidity and mortality.

\section{METHODS}

This is a hospital based retrospective case-control study conducted over 1 year, from March 2017 to February 2018 in the department of Obstetrics and Gynecology in Tribhuvan University Teaching Hospital. The study group comprises of all booked and unbooked adolescent pregnant ladies delivered after 28 weeks of pregnancy to the hospital during study period. The control group comprised of matched pregnant ladies of 20-30 years delivered in the same hospital in same period having the next entry in parturition register following a teenage pregnancy was selected. Pregnant women with less than 28 weeks of pregnancy, skeletal deformity and pelvic fracture were excluded from the study.

Permission for the study and ethical approval was obtained from institutional review committee (IRC) of Tribhuwan University, Institute of medicine (IOM) Ref No 4041(6-11) E2 /076/077. The data was obtained from the confinement book of the labour room and record section of the hospital. The maternal complications like anaemia, hypertensive disorder of pregnancy, intrauterine growth restriction, oligohydramnios, diabetes in pregnancy and mode of delivery and perinatal outcome like low birth weight, NNU admission, apgar score $<7$ were analysed between adolescent pregnant women and pregnant women between 20-30 years of age. Anemia was defined as a hemoglobin level below $11 \mathrm{gm} \%$ in the last trimester of pregnancy. Hypertensive disorder of pregnancy was defined as BP $>140 / 90 \mathrm{~mm}$ hg on the occasions apart after 20 weeks of pregnancy. Oligohydramnios was defined as reduced amniotic fluid (amniotic fluid index of $5 \mathrm{~cm}$ and less). Intrauterine growth restriction was defined as deviation and reduction in expected fetal growth $<10^{\text {th }}$ percentile for gestational age. Preterm labour was defined as defined as delivery before 37 weeks of gestation. Low birth weight was defined as baby weight less than 2500gm.

All collected data were recorded and entered master chart. Data analysis was done using SPSS software. Statistical tests carried out for testing the significance were the chi-square test and exact fischer test. Value of $\mathrm{P}<0.05$ was taken to indicate significance.

\section{RESULTS}

The total number of deliveries were 4980 during the study period out of which teenage pregnancy were 140 (2.81\%). Most of teenage pregnant women were of $18-19$ years of age (87.85\%). The minimum age of adolescent pregnancy was 15 . Adolescent pregnant women were mostly primigravidas $(85 \cdot 71 \%)$.

TABLE 1: Distribution of pregnant women according to antenatal complications

\begin{tabular}{|l|c|c|c|}
\multicolumn{1}{c|}{$\begin{array}{c}\text { Antenatal } \\
\text { Complications }\end{array}$} & $\begin{array}{c}\text { Adolescent Pregnant } \\
\text { women n(\%) }\end{array}$ & $\begin{array}{c}\text { Pregnant women } \\
\text { of 20-30 yrs n (\%) }\end{array}$ & P value \\
\hline Anemia & $23(16.42 \%)$ & $12(8.57 \%)$ & $0.02(\mathrm{~S})$ \\
\hline $\begin{array}{l}\text { Hypertensive disorder of } \\
\text { pregnancy(HDP) }\end{array}$ & $8(5.71 \%)$ & $2(1.42 \%)$ & 0.05 \\
\hline $\begin{array}{l}\text { Intrauterine growth } \\
\text { restriction(IUGR) }\end{array}$ & $8(5.71 \%)$ & $2(1.42 \%)$ & 0.05 \\
\hline Oligohydramnios & $5(3.57 \%)$ & $2(1.42 \%)$ & 0.44 \\
\hline Malpresentation & $5(3.57 \%)$ & $2(1.42 \%)$ & 0.44 \\
\hline Diabetes & $1(0.71 \%)$ & $2(1.42 \%)$ & 1.0 \\
\hline
\end{tabular}


Anaemia was significantly higher in teenage pregnant women than pregnant women of 20-30 years. HDP and IUGR were found high among adolescent pregnant women than adult pregnant women though not significant. Oligohydramnios and malpresentation were also more among adolescent pregnancy. Diabetes was found more in adult pregnant women than adolescent pregnancy though not significant. (Table 1)

TABLE 2: Distribution of pregnant women according to mode of delivery $(n=140)$

\begin{tabular}{|l|c|c|c|}
\hline \multirow{2}{*}{ Mode of delivery } & $\begin{array}{c}\text { Adolescent pregnant } \\
\text { women }\end{array}$ & $\begin{array}{c}\text { Pregnant women } \\
\text { of 20-30 yrs. }\end{array}$ & P value \\
\cline { 2 - 4 } & $\mathrm{n}(\%)$ & $\mathrm{n}(\%)$ & $0.021(\mathrm{~S})$ \\
\hline Preterm delivery & $18(12.85 \%)$ & $7(5 \%)$ & $0.000(\mathrm{~S})$ \\
\hline Vaginal delivery & $71(50.71 \%)$ & $105(77.85 \%)$ & 0.684 \\
\hline Instrumental delivery & $4(2.85 \%)$ & $2(1.42 \%)$ & $0.001 \quad(\mathrm{~S})$ \\
\hline Cesarean section & $47(33.57 \%)$ & $22(15.71 \%)$ & \\
\hline
\end{tabular}

Preterm delivery, cesarean section was found significantly higher in adolescent pregnant women than adult pregnant women. Vaginal delivery was significantly higher in adult pregnant women than adolescent pregnant women. (Table 2)

TABLE 3: Distribution of pregnant women according to perinatal complications

\begin{tabular}{|l|c|c|c|}
\hline \multirow{2}{*}{ Perinatal complication } & $\begin{array}{c}\text { Adolescent preg- } \\
\text { nant women }\end{array}$ & $\begin{array}{c}\text { Pregnant women of } \\
\mathbf{2 0 - 3 0} \text { yrs }\end{array}$ & P value \\
\cline { 2 - 4 } & $\mathbf{n}(\%)$ & $\mathbf{n}(\%)$ & $0.047(\mathrm{~S})$ \\
\hline Low birth weight (LBW) & $23(16.42 \%)$ & $12(8.57 \%)$ & 0.053 \\
\hline Apgar score at 5 min $(<7)$ & $8(5.71 \%)$ & $2(1.42 \%)$ & 0.053 \\
\hline Neonatal unit admission & $8(5.71 \%)$ & $2(1.42 \%)$ & 0.684 \\
\hline Still birth & $4(2.85 \%)$ & $2(1.42 \%)$ & \\
\hline
\end{tabular}

Low birth weight (LBW) baby were found significantly higher in adolescent pregnant women than adult pregnant women. (Table 3)

\section{DiSCUSSION}

Adolescent pregnancy continues to be a major public health problem in Nepal. In our study we got incidence of teenage pregnancy as $2.81 \%$ which was comparable to incidence noted by Rajoriya et al. $2.5 \%^{13}$ and Ambedkar et al. 3.9\%. ${ }^{14}$ In our study we found $16.42 \%$ teenagers were anemic which was lower than other study being 22-75\%. ${ }^{15,16}$ Incidence of anemia was low in our study may be due to the study site being referral tertiary hospital of capital city. We found $5.7 \%$ of teenage mothers had hypertensive disorder of pregnancy in our study while other studies found found incidence of $14.87 \% .{ }^{17}$ Intrauterine growth retardation was found higher in teenage mothers (5.71\%) than adult population (1.42\%) which was similar to study carried out by kyastha et al. ${ }^{18}$ The probable cause of IUGR and other foetal complications in teenage pregnancy was due to more cases of anaemia and hypertensive disorder of pregnancy. In our study oligohydramnios was found more in adolescent mother than adult mother $3.57 \%$ vs 1.42\%) but it was found same in both group in study carried out by Kovavisarach et al ${ }^{19}$ ( $0.6 \%$ vs $0.6 \%$ ). $12.85 \%$ of adolescent mothers delivered preterm which was similar in the findings of Rajoria $\mathrm{M}$ et al 13(13\%), Mamatha et al (12.5\%). ${ }^{20}$ This could be due to high incidence of anemia and preeclampsia in 
teenage pregnant women.Teenage mother underwent significant higher lower segment cesarean section as compared to adult mother in our study (33.57\% vs $15.71 \%)$ which was similar to study carried out by Nair A et al. ${ }^{17}$ As the teenagers are still in the growing stage, inadequate growth of pelvic bone could be the more cesarean section due to cephalopelvic disproportion. Vaginal delivery was significantly higher in adult pregnant women $(77.85 \%)$ than adolescent mother $(50.71 \%)$ in our study which was similar to study carried by Shravage JC et al (51.9\% and 21.4\% respectively). ${ }^{21}$ The probable reason for this may be due to immaturity and underdeveloped bony pelvis in teenagers.

We found $16.42 \%$ of babies born to teenagers were low birth weight but other study showed much higher incidence $29.49 \% .{ }^{17}$ Poor antenatal care, anaemia, HDP, and preterm labour could be the cause of low birth weight babies in teenage pregnancy. Apgar score $<7$ in 5 min and higher neonatal ward admission were higher in teenage mother than adult mother in our study which was similar to other study ${ }^{19}$ Stillbirth was found higher in teenage group in our study though not significant.

\section{CONClusion}

From the present study, it is concluded that teenage mothers had significant number of complications in pregnancy including leading cause being anaemia, HDP, and preterm labour compared to pregnant women in 20s. Maternal morbidity was also more due to increased operative interference. Perinatal morbidity was more due to high neonatal admission in teenage women.

\section{Conflict of interest: None}

\section{REFERENCES}

1. World Health Organization. Towards adulthood: exploring the sexual and reproductive health of adolescents in South Asia. World Health Organization; 2003.

2. United Nations Fund for Population Activities. Girlhood, Not Motherhood. Preventing Adolescent Pregnancy. UNFPA; 2015.

3. Darroch JE, Woog V, Bankole A, Ashford LS, Points K. Costs and benefits of meeting the Contraceptive needs of adolescents. Guttmacher Institute. 2016 May.

4. Pokharel G. Reaching adolescents with health services in Nepal. Bull World Health Organ. 2017;95:90-1.

5. Nepal Law Commission, The Muluki Ain ( General Code) ( Nepal). Vol 30. Kathmandu Nepal: 1963:11409.

6. Nepal MO. New ERA, ICF International. Nepal demographic and health survey. 2011.

7. Saloi M, Baruah KK, Ojah J. A study of factors associated with teenage pregnancies in comparison with pregnant women of 20-29yrs in Boko, Assam. Int J Health Sci Res. 2017; 7(4):18-22.

8. Kale KM, GS AN, Bila Walkar JS. Socio-medical correlates of teenage pregnancy. J Obstet Gynecol India. 1996 Apr;46:180-4.

9. Pal A, Gupta KB, Randhawa I. Adolescent pregnancy: a high risk group. Journal of the Indian Medical Association. 1997 May;95(5):127-8.

10. Canbaz S, Sunter AT, Cetinoglu CE, Peksen Y. Obstetric outcomes of adolescent pregnancies in Turkey. Advances in therapy. 2005 Nov 1;22(6):636-41.

11. Harrison KA, Rossiter CE, Chong Chong H. Relations between maternal height, fetal birth weight and cephalopelvic disproportion suggest that young Nigerian primigravidae grow during pregnancy. British Journal of Obstetrics and Gynaecology. 1985;92(Suppl 5):40ą48. 
12. Braine T. Adolescent pregnancy: a culturally complex issue. World Health Organization. Bulletin of the World Health Organization. 2009 Jun 1;87(6):410.s

13. Rajoriya M, Kalra R. The challenges of motherhood in adolescent girls. International Journal of Reproduction, Contraception, Obstetrics and Gynecology. 2015;4(3):697 DOI: 10.18203/2320-1770. ijrcog20150076

14. Ambadekar NN, Khandait DW, Zodpey SP, Kasturwar NB, Vasudeo ND. Teenage pregnancy outcome: a record based study. Indian J Med Sci. 1999 Jan;53(1):14-7. PMID: 10798019.

15. Kumar A, Singh T, Basu S, Pandey S, Bhargava V. Outcome of teenage pregnancy. The Indian Journal of Pediatrics. 2007 Oct;74(10):927-31.

16. Devi PP, Deedi MK, Swamy CG, Sarojini V. Risk of low birth weight infants in teenage pregnancy. Journal of Evolution of Medical and Dental Sciences. 2014 Oct 13;3(52):12164-70. DOI: 10.14260/ jemds/2014/3605

17. Nair A, Devi S. Obstetric outcome of teenage pregnancy in comparison with pregnant women of 20-29 years: a retrospective study. Int $J$ Reprod Contracept Obstet Gynecol. 2015;4(5):1319-23. https://doi. org/10.18203/2320-1770.IJRCOG20150703

18. Kayastha S, Pradhan A. Obstetric outcome of teenage pregnancy. Nepal Journal of Obstetrics and Gynaecology. 2012;7(2):29-32.

19. Kovavisarach E, Chairaj S, Tosang K, Asavapiriyanont S, Chotigeat U. Outcome of teenage pregnancy in Rajavithi Hospital. Medical journal of the Medical Association of Thailand. 2010 Jan 1;93(1):1. http://www.mat.or.th/journal

20. Mamatha S. Adolescent pregnancy: trends and determinants. Journal of Evolution of Medical and Dental Sciences. 2014 Oct 30;3(57):12910-27.Shravaje JC. Maternal and perinatal outcome in teenage pregnancy as compared to primigravida aged 20-29 years: A cross sectional study. J of Obs and Gynae. 2000;7:32-43. 